\title{
Renal Vein or Vena Cava Thrombosis or Other Coagulopathies
}

National Cancer Institute

\section{Source}

National Cancer Institute. Renal Vein or Vena Cava Thrombosis or Other Coagulopathies. NCI Thesaurus. Code C159322.

A section header for renal vein or vena cava thromboses or other coagulopathies. 